\title{
A perda do filho: luto e doação de órgãos ${ }^{1}$
}

\section{Loss of a child: grief and the donation of organs}

\author{
Ana Luiza Portela BITTENCOURT ${ }^{2}$ \\ Alberto Manuel QUINTANA ${ }^{2}$ \\ Maria Teresa Aquino de Campos VELHO3
}

\begin{abstract}
Resumo
O presente artigo constitui uma reflexão teórica que visa compreender os aspectos presentes no processo de luto parental pela perda do filho. Com base na compreensão do sofrimento decorrente dessa vivência, busca-se pensar suas implicações no procedimento de doação de órgãos e na postura que os profissionais da saúde podem assumir, a fim de amenizar o sofrimento dos pais diante da possibilidade de seu filho ser um potencial doador. Busca-se também abarcar princípios éticos referentes ao processo de consentimento da doação, assim como refletir sobre a capacitação da equipe de saúde para auxiliar os familiares na vivência do luto e no processo de doação de órgãos.
\end{abstract}

Unitermos: Doação de órgãos. Ética. Luto. Pais.

\begin{abstract}
This article consists on a theoretical reflection which aims to understand the issues involved in the process of parental grieffor the loss of their child. Through understanding the suffering caused by this experience we try to think about its implication regarding the organ donation procedure and the attitude that health professionals may assume to relieve parents suffering concerning the possibility of having their child as a potential donor. It also aims to cover ethical principles regarding the donation consenting process as well as to reflect about training the health care team to assist the family throughout grief and the organ donation process.
\end{abstract}

Uniterms: Tissue Donation. Ethics. Grief. Parents.

Este trabalho constitui uma reflexão teórica acerca de alguns aspectos que perpassam o processo de doação de órgãos, enfatizando a perspectiva parental diante de tal vivência. Buscou-se pensar sobre o sofrimento advindo da perda do filho e como esse sentimento se apresenta quando existe a possibilidade de doação. Fez-se inevitável pensar nos aspectos éticos que envolvem o processo, principalmente no momento da abordagem dos pais, ao se tentar obter seu consentimento para a captação, e, ainda, como a equipe de saúde pode auxiliar as famílias nesse momento crítico.

Desde crianças as pessoas são levadas a crer em uma espécie de sequência evolutiva. Quem estaria disposto a contrariar as aulas de Biologia quando é mos-

$\nabla \nabla \nabla \nabla$

1 Apoio: Conselho Nacional de Desenvolvimento Científico e Tecnológico e Coordenação de Aperfeiçoamento de Pessoal de Nível Superior

2 Universidade Federal de Santa Maria, Núcleo de Estudos Interdisciplinares em Saúde. Av. Roraima, 1000, Cidade Universitária, Camobi, 97105-900, Santa Maria, RS, Brasil. Correspondência para/Correspondence to: A.L.P. BITTENCOURT. E-mail: <alportelab@gmail.com>.

3 Universidade Federal de Santa Maria, Curso de Medicina. Santa Maria, RS, Brasil. 
trada uma lei da natureza que diz que todo ser vivo nasce, cresce, reproduz-se e morre? Tal encadeamento quase não deixa margem para questionamentos. Assim será! Após o nascimento o bebê recebe os cuidados dos pais até que esteja suficientemente crescido e independente, em seguida encontrará parceiros com quem reproduzir a fim de perpetuar a espécie, cuidará da prole assim como seus pais o cuidaram e, por fim, morrerá deixando seus filhos continuarem a evolução da espécie.

No entanto, a vida não segue um curso linear. Aqueles que ainda não cumpriram a sequência que foi a todos ensinada também morrem. Como entender e assimilar que os filhos podem partir antes dos pais? Como alterar o imaginário de uma sequência evolutiva quase perfeita? Tais questões, já complexas por si mesmas, podem comportar matizes ainda mais difíceis de serem pensados, trazidos pelas novas tecnologias, como a possibilidade de transplantar órgãos de mortos para vivos.

O enfrentamento da morte de um filho é demasiadamente sofrido e, quando se apresenta a possibilidade de que seus órgãos sejam doados, o sofrimento pode ser ainda maior. Diante dos pais se apresentará uma equipe apressada, lutando contra o tempo a fim de salvar outra vida. Mas quem se preocuparia com a vida do filho de outrem, quando Ihe foi tirada a vida do seu próprio rebento? Nessa situação, toda ação da equipe que promove a captação de órgãos pode parecer uma afronta a um ferimento ainda aberto e pulsante. Como lidar com a família que sofre a perda do filho, que precisa ser abordada para decidir sobre a integridade do corpo (já sem vida) dessa pessoa que, para ela, ainda é uma criança indefesa, independentemente da idade cronológica? Propõe-se, neste estudo, refletir sobre as questões que envolvem o processo de doação de órgãos, voltando-se o foco da discussão para a vivência parental do luto. Enfatiza-se também a necessidade de se pensarem as condutas que a equipe deve tomar, a fim de que esse momento não seja ainda mais traumatizante do que já é.

Além disso, o avanço dos conhecimentos médicos, bem como a complexidade das pesquisas e procedimentos assistenciais, cria a necessidade cada vez maior de uma reflexão sobre os aspectos éticos e morais envolvidos nesse processo. Acredita-se que, mais do que pensar sobre como a equipe pode contribuir para a decisão de doar os órgãos, é preciso que se reflita sobre como esses profissionais podem auxiliar a família do doador a enfrentar o sofrimento pelo qual passam, tomando a decisão que melhor se ajuste a seus ideais.

\section{Uma sequência quase perfeita: a morte e a realidade do luto}

Eizirik, Kapczinski e Bassols (2001), no livro"O Ciclo da vida humana: uma perspectiva psicodinâmica" abordam aspectos relativos a diferentes estágios do desenvolvimento humano, colocando a abordagem da morte no último capítulo, intitulado "A morte: última etapa do ciclo vital". De fato, é dessa forma que se compreende o ciclo vital, no qual a morte é posta como evento último, e numa perspectiva individual: afinal, morrer significa o fim da vida do indivíduo enquanto organismo. No entanto, a morte é também vivida socialmente, trazendo repercussão no desenvolvimento daqueles que cercam o morto: pais, irmãos e amigos estão em diferentes fases e são afetados de diferentes formas, dependendo de fatores tanto pessoais quanto relativos ao indivíduo que morreu, e de como esse fato se deu. Os autores ainda apresentam um capítulo referente ao ciclo de vida da família, apontando estágios pelos quais muitas delas passam, como o casal com filhos adolescentes, a síndrome do ninho vazio, o divórcio e os recasamentos. No entanto, menções a possíveis perdas ao longo desse ciclo são preteridas em favor de outros tópicos. A morte parece ser negada enquanto possibilidade antes da completude do ciclo de vida, sendo pensada apenas em relação ao avanço da idade, enquanto fim inevitável, porém passível de esquecimento ao longo da juventude.

Autores como Cordiolli (1998) nomeiam tais circunstâncias como "crises situacionais" que podem vir a abalar a dinâmica familiar, fazendo a família carecer de apoio terapêutico. A menção de tal vivência como uma "crise situacional" mostra uma concordância com o fato de que a morte constitui, atualmente, um elemento de medo e até pavor (Silva, Weiss, Bernardes \& Souza, 2006). Inconcebível como possibilidade real de ocorrência, a morte é sentida como um elemento estranho que ceifa a vida artificialmente, pois, a princípio, o viver é entendido apenas enquanto continuidade, ou seja, um encadeamento de acontecimentos. 
O corte em tal encadeamento é incompreensível, demanda explicações racionais e deixa o ser humano à deriva, esperando, confuso, o que estará reservado para si. Diante desse vazio de elucidações, o medo é inevitável e muitas vezes paralisante, tornando a indicação de apoio terapêutico bem-vinda para aqueles que se encontram nessa situação, em decorrência do falecimento de uma pessoa que Ihe era cara. Pontua-se nesse caso que, além da perda, é possível que o sujeito se sinta completamente desamparado por aqueles que o cercam, mesmo que de fato isso não ocorra.

Vê-se, então, que a morte é hoje um tema delicado, mesmo diante daqueles com quem se tem maior intimidade. Evita-se tocar no assunto e qualquer dúvida ou angústia relativa ao morrer é rechaçada e tratada com indiferença, como se o homem fosse imortal. Qualquer reflexão a respeito do morrer é tratada como mera perda de tempo. O homem passou a ver o adoecer como algo natural, enquanto o morrer se constitui como fatalismo, numa atitude clara de negação à morte (Silva \& Ruiz, 2003).

Hennezel levanta a questão afirmando que "o mundo que nos rodeia não nos ensina a morrer... Tampouco nos ensina a viver. No máximo a ter êxito na vida, o que não é a mesma coisa" (Hennezel, 1999, p.17). Essa colocação é uma triste constatação sobre uma sociedade que não tem tempo para demonstrações de fraqueza, e na qual aquele que sofre é aquele que não produz e, portanto, é visto como "uma pedra no caminho" dos demais.

É cada vez mais forte a necessidade de se estar sempre produzindo, formando uma espécie de memorial de si:"o que você deixou para o mundo?" A cobrança de que se deve ser plenamente realizado e feliz impõe a necessidade de mais tempo para se provar que é possível alcançar esse esperado estágio de felicidade plena. Talvez aí se denuncie o choque maior quando da morte do jovem e, principalmente, da criança. Em ambos os casos teve-se pouco tempo de vida para provar ao mundo o quanto se era capaz.

A morte precoce traz também o medo de um mundo injusto, pois se deseja acreditar que só aqueles que têm pecados é que morrem, ou que só os pecadores sofreram nesse processo. $\mathrm{O}$ que teria feito uma criança de tão horrível para merecer a morte? A morte do jovem choca por sua prematuridade, pela não realização de sonhos almejados e ainda pelo sentimento de que ele não teve tempo de alcançar a felicidade. De fato, é difícil a abordagem do tema morte quando o indivíduo se sente ainda cheio de vida ou crê que, devido à incompletude de sua evolução (da forma como concebida habitualmente), ainda tem muito potencial para conquistas e realizações. Como diz Luft (2003), as pessoas não querem perder nada - nem a saúde, nem afetos, nem aqueles que amam. Porém, a realidade humana é feita de constantes alternâncias, de perdas e ganhos; a perda dói, e essa dor, segundo a autora, incomoda, numa sociedade que não pode parar.

Muitas já foram as crenças estabelecidas a respeito da morte. Alguns povos a viram como força ou capricho divino, outros como algo não natural. Hoje se pode compreender o evento como parte do curso natural da vida. Nenhuma dessas compreensões, no entanto, aliviou o temor do ser humano diante do fim de sua existência. A finitude da vida é negada pela grande maioria das pessoas e, mesmo que não se negue esse fato, a morte de uma pessoa próxima é chocante, como se ela nunca devesse morrer. Assim, a surpresa diante da morte parece estar colocada, não no fato de se desconhecer que toda a vida tem fim, mas sim na necessidade de se enfrentar a própria finitude.

Desde a Idade Média até o século XIX a atitude diante da morte modificou-se. Se antes esse evento era considerado familiar, agora ele passou a ser motivo de vergonha. A necessidade social de que os sujeitos aparentem constante felicidade leva à evitação daqueles que cercam o morto, pois podem abalar a ilusão de uma vida plenamente feliz. A emoção advinda da perda de um amigo ou parente deve ser escondida (Ariès, 1977).

Só o luto coletivo é aceito hoje, como uma espécie de confraternização universal numa sociedade individualista. A morte de uma celebridade torna-se um culto universal, no qual todos podem unir-se em sua dor. Porém, o direito ao choro por uma perda individual não é dado, é recriminado, visto até como hostil, um enfrentamento à "felicidade geral da nação". Como alguém poderia atrever-se a demonstrar tristeza? Mesmo sofrendo, as pessoas fingem indiferença, como uma forma de não se diminuir diante dos preconceitos sociais, pois mostrar o luto tornou-se uma desvantagem (Chiavenato, 1998). 
O sofrimento pela perda de alguém pode trazer profunda angústia ao sujeito enlutado. Caso dê demonstrações excessivas de sua tristeza, será excluído. Do contrário, se a manifestação for muito discreta, o individuo será condenado pelo desamor àquele que morreu. Afinal, em que medida se deve expressar o luto?

Hennezel (1999) cita as inúmeras correspondências recebidas em decorrência de um texto publicado por ela acerca da morte. As cartas relatavam o sofrimento decorrente do silêncio diante da morte, da evitação em acompanhar amigos e familiares no processo de morrer - uma fuga talvez decorrente da própria incapacidade desses sujeitos em enfrentar a dor que essa vivência provocava em si mesmos. Os relatos mostram que nem mesmo a evasão evita a dor. Não enfrentar a morte, nem as aflições que possam se originar dessa reflexão, também gera consternação. Como aponta Ariès: "A proibição do luto leva o sobrevivente a aturdir-se com o trabalho ou, ao contrário, a atingir o limite da loucura" (Ariès, 1977, p.151).

O luto constitui um processo de reconstrução, de reorganização diante da morte (Franco \& Mazorra, 2007). Oliveira e Lopes (2008) o definem como a fase da expressão dos sentimentos decorrentes da perda, constituindo-se no conjunto de reações dela advindas. Ele não deve ser ignorado pelos profissionais, e sim ser valorizado e devidamente acompanhado. Os autores acreditam que o luto é importante, pois permite o entendimento de que a morte é real, possibilitando, a partir daí, o estabelecimento de novas concepções sobre o mundo. Quando não existem espaços para que a família se expresse, o sentimento de solidão se amplia, trazendo sofrimento e angústia (Silva et al., 2006).

\section{A perda do filho: culpa e doação}

Como exposto, a morte de uma pessoa jovem é interpretada como a interrupção de seu ciclo biológico, provocando, naqueles que ficam, sentimentos de fracasso e frustração. A superação da perda causada pela morte não é uma tarefa fácil, sendo ainda pior quando esta ocorre prematuramente (Alarcão, Carvalho \& Pelloso, 2008).

Convém assinalar que a percepção de juventude muitas vezes é relativa, principalmente quando abordada em relação à morte. No caso da morte dos filhos, inevitavelmente, os pais a encararam como uma perda precoce. Socialmente entende-se que os pais deveriam morrer primeiro, por terem mais idade e estarem em um estágio mais avançado que os filhos em relação ao ciclo biológico.

A morte de um filho ultrapassa a compreensão simplesmente biológica, tornando-se também um processo cognitivo e emocional. Sua compreensão requer a construção de uma nova realidade para a família, cujo filho, investido de grandes expectativas em relação ao futuro, já não existe (Bousso, 2008). Uma realidade como essa é considerada "uma monstruosidade que vai contra a ordem natural das coisas" (Bolze \& Castoldi, 2005, p.80). Os autores também afirmam que o luto parental costuma tomar proporções de sofrimento muito intensas, afetando, além da esfera individual, o relacionamento com o parceiro e também a dimensão social.

A dor provocada pela morte só existe se a individualidade do morto estiver presente e for reconhecida: quanto mais próximo afetivamente do enlutado, maior a dor provocada (Morin, 1976). Diante disso, Oliveira e Lopes (2008) refletiram sobre o sofrimento decorrente da perda de um filho. Afinal, mais do que conviver com essa figura, os pais a geraram, estabelecendo com ela uma relação de quase dependência. Os autores acreditam que tal evento pode significar, para os pais, o fracasso, a falha de um amor que fantasiosamente cura e protege, pois aquele que ama não deixa que nada aconteça ao ser amado.

Nesse contexto, a doação de órgãos significa a admissão da morte do filho num momento em que a família ainda não é capaz de aceitá-la (Bousso, 2008). Aceitar a doação de órgãos é deixar de investir na possibilidade de que o sujeito volte a viver. Dado que o possível doador ainda apresenta batimentos cardíacos e respira com a manutenção de equipamentos que viabilizam esse estado, a permissão para a retirada dos órgãos pode ser encarada como uma sentença de morte emitida pelos pais a seu próprio filho. Os familiares costumam mostrar, em geral, medo de que a pessoa ainda esteja viva, sentindo-se responsável pelo desligamento dos aparelhos (Sadala, 2001).

Eis aí outro aspecto gerador de culpa, desta vez decorrente de um elemento artificialmente colocado ao lado da situação de perda. Diz-se artificialmente porque a doação de órgãos é uma realidade recente e 
não constitui elemento inerente à morte. Ou seja, essa perspectiva não fazia parte desta realidade. A perda do ente querido não gerava maiores preocupações quanto ao destino de seu corpo; afinal, cada sociedade tinha, e tem, rituais próprios que se seguem à morte e que são seguidos sem maiores percalços. Hoje, porém, a doação é inserida como possibilidade em muitos casos, quando o familiar será abordado a fim de que decida sobre a aceitação ou não do procedimento.

Em pesquisa realizada com familiares de doadores de órgãos em 1998, no estado de São Paulo, Sadala (2001) verificou que a notícia impactante da morte do doador é acompanhada pelo pedido de doação de seus órgãos, sendo este interpretado por alguns familiares como uma consulta sobre o destino que terão os restos mortais do falecido. A culpa por ter talvez causado algum dano ao doador mostra-se presente na vivência do familiar que autoriza a doação, tendo alguns participantes da pesquisa relatado não conseguir dormir devido a tais preocupações.

Isso mostra que a família do doente também precisa de atenção e necessita ser ouvida, pois diversas mudanças se dão nesse contexto. Modificações de papéis muitas vezes são necessárias e difíceis de aceitar, podendo causar ressentimentos. Os familiares também devem ser auxiliados a manter sem culpa as suas atividades normais. É importante conversar com esses sujeitos a fim de aliviar esse sentimento, de descobrir o que esta por trás dele, pois pode até mesmo levar a transtornos somáticos, se não expresso devidamente (Kübler-Ross, 2002).

Durante o processo de consentimento, o entendimento a respeito da situação de morte encefálica (condição para a realização de transplantes) é fator determinante para a disposição da família em considerar a doação de órgãos ou não. A família é capaz de entender esse conceito, mas precisa de tempo para que ele faça sentido em sua realidade. A não viabilização desse tempo pode dificultar a compreensão da situação e atrapalhar a relação com a equipe de saúde que auxilia no processo de captação de órgãos. Esta última tem um entendimento diverso sobre a questão, e, se não a conduzir adequadamente, pode levar à recusa da doação de órgãos. Famílias que recusaram o procedimento referiram uma abordagem precoce, pois ainda se encontravam num momento de preocupação, amedrontados e exaustos. A forte situação emocional experimentada pelas famílias pode dificultar a compreensão das palavras da equipe que as abordou solicitando a doação de órgãos (Bousso, 2008).

Rech e Rodrigues Filho (2007) acreditam que o momento ideal para abordar a família seja, realmente, após a informação do diagnóstico de morte encefálica, porém, a informação deve ser seguida da possibilidade de esclarecimentos das dúvidas expressas pelos familiares. Após essa comunicação dever-se-ia possibilitar à família um período para refletir e, somente após, outra equipe entraria em contato para solicitar a doação. Isso deveria acontecer num local apropriado, sem pressa e respeitando a decisão tomada.

\section{Aspectos éticos relevantes}

Todo o processo de doação, desde a abordagem do familiar à captação do órgão e realização do transplante, é bastante complexo. O profissional da saúde representa a figura de poder na relação com o paciente e sua família, cabendo a ele assumir o compromisso do bom uso de seu saber a serviço da saúde e bem-estar daqueles que buscaram sua ajuda. É necessário que esses sujeitos reflitam sobre os princípios éticos que perpassam essa relação, para que suas atitudes e comportamentos representem os ideais postos pela ética.

Ao falar sobre a abordagem que a equipe faz à família está-se também falando acerca do processo de consentimento informado. Este não deve ser confundido com a simples assinatura de um papel, pois ele visa garantir a autonomia do sujeito, no caso, o familiar ou os pais do possível doador (Biondo-Simões, Martynetz, Ueda \& Olandoski, 2007). A garantia é assegurada por meio do fornecimento de informação, pertinente e adequada, que possibilite a tomada de decisão de maneira voluntária, livre de pressões externas. Segundo o entendimento de Beauchamp e Childress (2002), em tais circunstâncias, o consentimento informado ocorre quando o familiar, tendo entendimento da situação, e livre de qualquer controle por parte de outro, intencionalmente autoriza o profissional a fazer algo, no caso, a retirada dos órgãos.

Para Clotet (1993), o consentimento informado é uma condição indispensável da relação médico- 
-paciente. Através dele o sujeito pode decidir de forma voluntária, autônoma e capaz, após um processo informativo e deliberativo, sabendo da natureza do procedimento ao qual irá se sujeitar e das consequências e riscos a que será submetido, tanto em caso de aceitar quanto de recusar a intervenção.

Podem-se destacar no processo de obtenção do consentimento duas noções principais: a informação e a voluntariedade. O consentimento não pode decorrer de erros ou vícios, não pode ser obtido por meio de coação, seja ela física, psíquica ou moral, nem pode ser conseguido por meio de simulação ou engano visando manipular os familiares do paciente, pois tais situações impedem a manifestação da livre vontade pessoal. Ressalta-se que as informações fornecidas devem ser claras e precisas. Informações falsas, incompletas ou mal entendidas podem resultar em defeitos de raciocínio, assim levando o indivíduo a formar opiniões baseadas em elementos irreais, de forma a comprometer a autonomia de sua decisão (Fortes, 1994). Assim, para que possam decidir sobre o destino do corpo do filho, os pais devem estar cientes de seu estado, precisam ter clareza quanto ao diagnóstico de morte encefálica, que é essencial para a definição do sujeito como doador em potencial (Bousso, 2008).

Quanto à voluntariedade, Goldim (2002) descreve-a como uma característica pessoal, pois ela permite ao sujeito optar entre diferentes alternativas segundo os ideais postos por suas próprias crenças, valores, interesses, desejos e objetivos. Tais elementos permitem que a decisão de cada pessoa seja única. Garantir a voluntariedade é dar ao sujeito a possibilidade de tomar decisões, sem ser constrangido ou coagido a decidir por uma das alternativas.

Ao ser coagido a tomar uma decisão, o familiar estaria abrindo mão de sua voluntariedade, ou seja, de tomar uma decisão que corresponda àquilo que acredita ser o correto para a situação. Se essa premissa não é respeitada, entende-se que o sujeito agirá de acordo com a perspectiva alheia, adotando atitudes que, muitas vezes, são contrárias às suas crenças. Tal perspectiva vai ao encontro das propostas de Rech e Rodrigues Filho (2007), que condenam as tentativas de convencimento dos familiares, pois acreditam que estes devem estar à vontade, não devendo sentir nem obrigação de doar, 440 nem culpa por não doar.
Uma avaliação positiva quanto ao processo de doação parece estar relacionada ao fato de os familiares terem tomado a decisão de forma consciente e com o desejo genuíno de doar. Quando, ao contrário, a decisão se baseia em pressões externas, a experiência tende a ser traumática e avaliada como negativa (Sadala, 2001). Esta observação coincide com o que foi encontrado nas pesquisas de Monahan et al. (1995) sobre o uso de coerção na assistência a saúde. Os autores, estudando pacientes psiquiátricos, observaram que, quando o sujeito percebe estar sendo controlado, apresenta algumas reações psicológicas, como depressão, ansiedade e interrupção de qualquer esforço pessoal a fim de aliviar uma situação aversiva. Sujeitos que se sentiram coagidos têm menor tendência a acreditar que a equipe irá ajudá-los. Logo, se o familiar sentir-se coagido ao decidir sobre a possibilidade da doação dos órgãos do filho, é possível que venha a expressar raiva e angústia, sentindo-se culpado por ter autorizado o procedimento contra suas crenças e ideais. Este fato pode contribuir para o aumento do sofrimento vivenciado por esses sujeitos.

\section{O papel da equipe de saúde}

Diante do que foi exposto, é preciso que se reflita a respeito de como a equipe pode auxiliar a família do doador a enfrentar o sofrimento pelo qual passa, tomando a decisão que melhor se ajuste aos seus ideais. Silva et al. (2006) acreditam que a morte do filho faz com que a família repense todo seu modo de vida, e nesse processo ela deve contar com o apoio de sua rede social e da equipe de saúde que atendeu o caso. Convém assinalar que a atuação da instituição foi avaliada negativamente pela maioria dos familiares entrevistados na pesquisa de Sadala (2001).

A equipe deve ser sensível e aprimorar sua aptidão para avaliar qual tipo de ajuda se faz necessária durante o processo de luto; afinal, este é diferente para cada cultura e para cada indivíduo, sendo impossível estabelecer um padrão de comportamento. No entanto, isso não impossibilita toda e qualquer ação da equipe de saúde, pois, por exemplo, a simples permissão da expressão emocional e a evitação da medicalização desnecessária podem beneficiar os sujeitos que vivenciam o processo de luto. Ao expressar seus sentimentos 
de raiva e angústia, o enlutado reafirma sua perda, o que o ajuda a elaborá-la (Oliveira \& Lopes, 2008).

A ajuda prestada aos pais, presente aqui como suporte afetivo, favorecerá sua integração emocional e interpessoal (Espíndula \&Valle, 2002). Trabalhos como o de Bousso (2008) mostram o quanto a família é favorecida quando o profissional que atende o filho é sensível à sua experiência, reconhecendo o sofrimento e acolhendo as dúvidas que possam estar presentes. Segundo a autora, uma relação baseada nesse tipo de atitude facilita aos pais o acesso ao suporte social, e, por meio do fornecimento das informações necessárias, a decisão a respeito da doação se dará com menos conflito.

Ainda, o estudo realizado por Sadala (2001) aponta que os familiares reclamam do descaso da equipe para com eles após a captação do órgão, o que, segundo essas pessoas, desestimula o processo de doação. Por tal motivo, a autora sugere que a família deve ser atendida no momento do luto e da perda. O abandono da família após a captação parece deixar os familiares com o sentimento de que foram usados e de que foi violado o corpo de seu filho por interesse. Mais uma vez, destaca-se a importância de se respeitar a resolução do sujeito, mesmo que contrária ao plano da equipe. Frise-se, todavia, que esse respeito não significa abandono; uma atitude repressora por parte da equipe pode intimidar esses sujeitos, inviabilizando, inclusive, futuros processos de doação de órgãos de outros membros da família que venham a falecer.

Pessini e Barchifontaine (1991/1996) apontam que, no Brasil, o maior impedimento para os transplantes é a recusa das famílias em doar os órgãos do parente em morte encefálica. Os autores salientam que a arrogância do corpo médico também é um empecilho para a doação de órgãos. Esses dados indicam que, para reverter o quadro de transplantes no país, além de investimento em divulgação e informação sobre o procedimento, deve-se investir no preparo da equipe em lidar com os familiares. A relação entre o paciente e os profissionais da saúde é sempre desigual. Devido a isso, a equipe deve responsabilizar-se pelo respeito a esse sujeito, sua autonomia e valores (Goldim, 2002).

Sabe-se que, muitas vezes, no dia a dia das instituições de saúde existem questões de cunho prático, como a pouca disponibilidade de tempo para atendimentos mais demorados, o que acaba por prejudicar a relação equipe/paciente. Porém, acredita-se que, se os profissionais estiverem bem preparados e possuírem uma boa rede de comunicação entre si, o acolhimento aos familiares enlutados pode acontecer de maneira mais eficaz e humana.

\section{Considerações Finais}

A morte do filho mostra-se como um evento de difícil assimilação para os pais. Observou-se na literatura analisada que essa perda é acompanhada pelo sentimento de culpa, que parece ter diferentes origens. Dentre elas, apontou-se a fantasia de falha do amor parental e a culpa pelo desinvestimento na vida do filho e pela mutilação de seu corpo.

É nesse contexto que a possibilidade de doação de órgãos está inserida. Portanto, não é difícil imaginar que, diante de tantos conflitos afetivos, os pais se neguem a doar os órgãos do filho. O evento é, muitas vezes, encarado como uma violência ao corpo daquele que se ama, contribuindo, assim, para aumentar o sofrimento dos que terão que tomar tal decisão. Assinalou-se também a barreira que se impõe em nossa sociedade com relação à expressão do luto, o que leva ao isolamento do sujeito enlutado, que sofre sem encontrar acolhimento por parte de seu grupo.

Acredita-se que, diante do que foi analisado na literatura, a equipe de saúde possa contribuir para o alívio desse sofrimento, ao possibilitar aos pais um acolhimento de suas angústias frente à morte do filho. Diante da possibilidade de este ser um doador em potencial, o simples processo de consentimento informado pode trazer grandes contribuições. Para isso, a equipe deve estar capacitada a realizar tal processo, disponibilizando de tempo para transmitir aos pais as informações necessárias acerca da doação de órgãos, mostrando-se acessível a suas dúvidas e aceitando suas decisões.

Além disso, observa-se que o sofrimento parental não se encerra com a decisão de doar ou não os órgãos do filho, podendo-se prolongar com a dúvida em relação ao que foi decidido. Desse modo, ressalta-se a importância de que os familiares sejam também acompanhados após a resolução, acolhidos em suas dúvidas e angústias e, caso necessário, encaminhados para serviços especializados de acompanhamento psicológico. 


\section{Referências}

Alarcão, A. C. J., Carvalho, M. D. B., \& Pelloso, S. M. (2008). The death of a young son in violent circumstance: understanding the experience of the mother. Revista Latino-Americana de Enfermagem, 16 (3), 341-347.

Ariès, P. (1977). História da morteno ociedente: da ldade Média aos nossos dias. Rio de Janeiro: F. Alves.

Beauchamp, T. L., \& Childress, J. F. (2002). Princípios de ética biomédica. São Paulo: Edições Loyola.

Biondo-Simões, M. L. P., Martynetz, J., Ueda, F. M. K., \& Olandoski, M. (2007). Compreensão do termo de consentimento informado. Revista Colégio Brasileiro de Cirurgiões, 34 (3), 183-188.

Bolze, S. D. A., \& Castoldi, L. (2005). O acompanhamento familiar antes e depois da morte da criança: uma proposta de intervenção para o psicólogo hospitalar. Aletheia, 21, 79-91.

Bousso, R. S. (2008). O processo de decisão familiar na doação de órgãos do filho: uma teoria substantiva. Texto Contexto - Enfermagem, 17 (1), 45-57.

Chiavenato, J. J. (1998). A morte: uma abordagem sociocultural. São Paulo: Moderna.

Clotet, J. (1993). Por que bioética? Bioética, 1 (1), 13-19.

Cordioli, A. (Org.). (1998). Psicoterapias: abordagens atuais. Porto Alegre: Artes Médicas.

Eizirik, C. L., Kapczinski, F., \& Bassols, A. M. S. (2001). O ciclo da vidahumana: uma perspectivepsicodinâmica. Porto Alegre: Artmed.

Espíndula, J. A., \& Valle, E. R. M. (2002). Experiência materna diante da iminência de morte do filho com recidiva de câncer. Pediatria Moderna, 38 (5), 188-194.

Fortes, P. A. C (1994). Reflexões sobre a bioética e o consentimento esclarecido. Bioética, 2, 129-35.

Franco, M. H. P., \& Mazzorra, L. (2007). Criança e luto: vivências fantasmáticas diante da morte do genitor. Estudos de Psi- cologia (Campinas), 24 (4), 503-511. doi: 101590/S1031 66×2007000400009.

Goldim, J. R. (2002). O consentimento informado numa perspectiva além da autonomia. Revista AMRIGS, $46(3,4)$, 109-116.

Hennezel, M. (1999). A arte de morrer: tradições religiosas e espiritualidade humanista diante da morte na atualidade. Petrópolis: Vozes.

Kübler-Ross, E. (2002). Sobre a morte e o morrer ( $8^{\text {th }}$ ed.). São Paulo: Martins Fontes.

Luft, L. (2003). Perdas \& ganhos. Rio de Janeiro: Record.

Morin, E. (1976). Ohomeme morte. Portugal: Europa América.

Monahan, J., Hoge, S. K., Lidz, C. W., Roth, L. T., Bennett, N., Gardner, W., et al. (1995). Coercion and commitment: understanding involuntary mental hospital admission. International Journal of Law and Psychiatry, 18 (3), 249-263.

Oliveira, J. B. A., \& Lopes, R. G. C. (2008). O processo de luto no idoso pela morte de cônjuge e filho. Psicologia em Estudo, 13 (2), 217-221.

Pessini, L., \& Barchifontaine, C. P. (1996). Problemas atuais de Bioética (3a ed.). São Paulo: Loyola.

Rech, T. H., \& Rodrigues Filho, É. M. R. (2007). Entrevista familiar e consentimento. Revista Brasileira de Terapia Intensiva, $19(1), 85-89$.

Sadala, M. L. A. (2001). A experiência de doar órgãos na visão de familiares de doadores. Jornal Brasileiro de Nefrologia, 23 (3), 143-51.

Silva, A. L. L., \& Ruiz, E. M. (2003). Cuidar, morte e morrer: significações para profissionais de enfermagem. Estudos de Psicologia (Campinas), 20 (1), 15-25. doi: 10.1590/S01 03-166X2003000100002.

Silva, L. C., Weiss, E., Bernardes, M. D. B., \& Souza A. I. J. (2006). Hospitalização e morte na infância: desafios das famílias. Família, Saúde e Desenvolvimento, 8 (1),73-79.

Recebido em: 9/12/2009

Versão final reapresentada em: 6/8/2010

Aprovado em: 7/2/2011 